\title{
Monitoramento de propriedades rurais através de dados multisensores em nível orbital
}

\author{
Monitoring of rural properties using multisensor satellite data
}

\author{
Rener Ribeiro Fernandes $\left.{ }^{1 *}\right)$ \\ Gustavo Manzon Nunes ${ }^{2}$ \\ Ronaldo Drescher ${ }^{3}$
}

\section{Resumo}

O presente estudo teve como objetivo realizar uma análise temporal das áreas alteradas em uma propriedade rural (Fazenda Santo Antônio do Jurigue), localizada no estado do Mato Grosso, por meio de dados de multisensores ao longo de 6 anos. Foram utilizadas imagens dos sensores: HRC/ CBERS-2B, ETM+/Landsat 7 e TM/Landsat-5 para análise temporal dos anos de 2002, 2004, 2006 e 2008. Após as etapas de pré-processamento realizadas nas imagens, foi aplicado o método de classificação supervisionada por máxima verossimilhança. $\mathrm{Na}$ imagem do ano de 2008, foi também aplicado o método de fusão de imagens IHS e o método de classificação orientada a objetos com o intuito de discriminar melhor o uso da terra da área de estudo, comparando seus resultados temáticos àqueles obtidos pela classificação por máxima verossimilhança. Os valores obtidos foram tabulados, verificando que no ano de $2002,33,43 \%$ da cobertura vegetal da propriedade já havia sido alterado, percentual esse que aumentou para 40,32\% em 2004, 51,85\% em 2006. Em 2008 essa conversão da tipologia vegetal natural atingiu valores de 60,69\% através da análise da classificação supervisionada por máxima verossimilhança e de 70,64\% para a classificação orientada a objetos. $\mathrm{O}$ método de classificação orientada a objetos foi o que apresentou resultados finais mais promissores, possibilitados pelo uso de dados de alta resolução do sensor HRC do satélite CBERS-2B.

Palavras-chave: monitoramento; degradação florestal; processamento digital de imagens.

I Engenheiro Florestal; Mestrando do Programa de Pós-Graduação em Ciências Florestais e Ambientais da Universidade Federal do Mato Grosso, UFMT; Endereço: Avenida Fernando Correa da Costa s/n, CEP: 78.000-000, Cuiabá, Mato Grosso, Brasil; E-mail: renerfernandes@florestal.eng.br (*) Autor para correspondência.

2 Dr.; Engenheiro Florestal; Professor do Departamento de Engenharia Florestal da Universidade Federal do Mato Grosso, UFMT; E-mail: gustavonunes@ufmt.br

3 Dr.; Engenheiro Florestal; Professor do Departamento de Engenharia Florestal da Universidade Federal do Mato Grosso, UFMT; E-mail: ronaldo_drescher@hotmail.com

Recebido para publicação em 16/08/2010 e aceito em II/04/20I I

\begin{tabular}{llllll}
\hline Ambiência Guarapuava (PR) v.7 n.I & p. 75 - 87 & Jan./Abr. 20II & ISSN 1808 - 025 I
\end{tabular}

DOI: $10.5777 /$ ambiencia.2011.01.06 
This study aimed to perform a temporal analysis of the rural property (Santo Antonio do Jurigue Farm), located in Mato Grosso by means of multisensor data over 6 years. We used images from the sensors: HRC/CBERS-2B, ETM+/Landsat 7 and TM/Landsat- 5 for temporal analysis of the years 2002, 2004, 2006 and 2008. After the preprocessing steps performed on the images was applied the method of maximum likelihood of supervised classification. In the image of 2008 was also applied the method of image fusion IHS classification and object-oriented in order to better discriminate the land use of the study area, comparing their results to those obtained by thematic classification by maximum likelihood. The values were tabulated, noting that in 2002, 33.43\% of the vegetation of the structure had been changed, this percentage increased to $40.32 \%$ in $2004,51.85 \%$ in 2006. In 2008 the conversion of natural vegetation type values up to $60.69 \%$ by analysis of supervised classification using maximum likelihood and $70.64 \%$ for object-oriented classification. The method of object-orientad classification showed the most promissing final results enabled by the use of high-resolution data of the sensor HRC satellite CBERS-2B.

Key words: monitoring; forest degradation; digital image processing.

\section{Introdução}

A ocupação do solo no país tem ocorrido, geralmente, de forma desordenada, como a supressão indiscriminada da cobertura vegetal nativa, ocorrendo perda de biodiversidade, degradação do solo e assoreamento, poluição e contaminação dos recursos hídricos. (BASEGGIO et al.,2006).

Há vários anos, as propriedades rurais do Estado de Mato Grosso vêm sofrendo com esse problema, pois estabeleceu-se um forte fluxo migratório para a região e aceleração da substituição da cobertura vegetal original por áreas agrícolas e pastagens. Neste âmbito de implantação dos sistemas de produção agrícola e pecuária o desmatamento é um processo inerente, intensificando a degradação.

Coelho et al. (2005) afirmam que os responsáveis pela implementação de estratégias de governo e pela elaboração de planejamentos regionais necessitam dispor de informações básicas sobre os recursos naturais, a fim de estabelecer uma política eficiente de controle e direcionamento das ações antrópicas, de fundamental importância ao desenvolvimento da economia e à melhor qualidade de vida. A implementação de uma correta política ambiental requer o conhecimento da distribuição espacial desses recursos, o que pode ser obtido por meio do mapeamento e inventário contínuo em épocas diferentes.

O estudo da componente temporal associado às informações espaciais e espectrais pode revelar os padrões e a complexidade de processos sobre a dinâmica de uso do solo e monitoramento ambiental (BRUZZONE et al., 2003). Figueiredo e Carvalho (2006) relatam que várias experiências e políticas públicas têm sido aplicadas para reverter este cenário, entre elas, as que objetivam o monitoramento ambiental da cobertura florestal e utilizam a aplicação de técnicas de classificação digital de imagens orbitais 
de sensoriamento remoto no mapeamento da cobertura da terra.

Considerando o avanço dos procedimentos de processamento digital necessários para detectar e delimitar alterações no meio ambiente, várias metodologias podem ser adotadas como, por exemplo, estudos realizados por Más (1998) que, a partir de dados LANDSAT/MSS, utilizou variadas técnicas de processamento digital como, diferenciação de imagens, diferenciação de índices de vegetação (NDVI), análise de componentes principais, comparação pósclassificação, tendo fotografias aéreas como fonte de avaliação da acurácia dos resultados, destacando que a técnica de pós-classificação apresentou significativo desempenho por indicar a natureza das mudanças. Maldonado et al. (2002), estudando uma região no semiárido brasileiro, fizeram uso de principais componentes (rotação controlada por matriz de covariância) em imagens multitemporais LANDSAT/TM (bandas do vermelho e infravermelho próximo), quantificando dois níveis de degradação, dois de recuperação da cobertura vegetal e um de não mudança. Lorena et al. (2002), ao utilizarem imagens LANDSAT/TM da região do projeto de colonização Pedro Peixoto (Acre), empregaram duas técnicas: a de Análise por Vetor de Mudanças (AVM) e a de comparação pós-classificação (algoritmo classificatório por regiões Battacharyya), indicando ganho e perda de biomassa, frente à conversão de áreas de floresta primária em áreas de atividades agrícola e de pecuária. Silva et al. (2003) fizeram uso dessa técnica AVM para caracterizar e quantificar a dinâmica de uso e cobertura da terra, em áreas de floresta tropical sob influência da atividade de exploração madeireira no Estado do Mato Grosso, utilizando imagens LANDSAT-7/
TM (bandas 1 a 5 e 7). Coppin et al. (2004) apresentaram uma revisão dos métodos atuais de deteç̧ão de mudanças aplicados ao monitoramento de ecossistemas no domínio óptico, com dados multisensores, fazendo uma análise crítica das técnicas nessa integração entre os dados sensoriados e os fenômenos biofísicos geradores das mudanças na paisagem investigada. Santos et al. (2005) demonstraram a aplicabilidade da técnica de "Rotação Radiométrica controlada por eixo de não-mudança" (RCEN), utilizando dados multitemporais do LANDSAT/ETM+ e CBERS-2/CCD em área da Amazônia sob domínio de floresta de transição.

A rápida evolução tecnológica de sensores remotos vem proporcionando a obtenção de dados digitais com uma resolução espacial cada vez maior (OLIVEIRA FILHO et al., 1998). A disponibilidade de imagens pancromáticas de alta resolução, tais como as do sensor HRC (High Resolution Camera) acoplado na plataforma do satélite sino-brasileiro CBERS-2B, que são distribuídas gratuitamente via internet pelo INPE (Instituto Nacional de Pesquisas Espaciais) aliada a técnicas de processamento digital de imagens, através dos métodos de realce, fusão e classificação, ampliam ainda mais a gama de aplicações e de determinação de alvos naturais na superfície terrestre.

Uma atividade desse nível seria de vital importância para um melhor gerenciamento das propriedades rurais, permitindo um planejamento adequado para o bom desenvolvimento social e econômico dessas áreas no Estado de Mato Grosso, inclusive implicando medidas para minimizar os possíveis impactos dessa degradação. Esse tipo de monitoramento serve como uma ferramenta de controle, podendo mostrar a ampliação do grau de conflito existente 
entre o crescimento econômico e o nível de fragmentação.

Nesse contexto, o presente trabalho teve como finalidade a realização de uma análise temporal das áreas alteradas em uma propriedade rural no estado de Mato Grosso, denominada Fazenda Santo Antônio do Jurigue, localizada no município de Pedra Preta, envolvendo os anos de 2002 a 2008.

Esse estudo foi realizado com a aplicação de duas técnicas de processamento digital de imagens de sensoriamento remoto: classificação por máxima verossimilhança e classificação orientada a objetos, com o intuito de discriminar o nível de alteração de sua cobertura vegetal bem como apresentar os resultados de quantificação de sua ARL (Área de Reserva Legal) considerando a sua definição real dada pelo Código Florestal (Lei $\mathrm{N}^{\circ} 4771 / 65$ ), em seu art. $1^{\circ}, \$ 2^{\circ}$, inciso III, inserido pela Media Provisória N ${ }^{\circ}$. 2.16667, de 24.08.2001, sendo: "área localizada no interior de uma propriedade ou posse rural, excetuada a de preservação permanente, necessária ao uso sustentável dos recursos naturais, à conservação e reabilitação dos processos ecológicos, à conservação da biodiversidade e ao abrigo e proteção de fauna e flora nativas". A delimitação dos percentuais previstos encontra-se no artigo 16, em seus incisos I, II, III e IV que, respectivamente, estabelecem um percentual de $80 \%$ para a Amazônia Legal, 35\% na propriedade rural situada em área de cerrado, que será o caso abordado na referida área de estudo.

\section{Material e Métodos}

\section{Localização da Área de Estudo}

A área objeto de estudo situa-se na porção sul do estado de Mato Grosso, no município de Pedra Preta. Posiciona-se entre as latitudes $16^{\circ} 47^{\prime} \mathrm{S}$ e $16^{\circ} 41^{\prime} \mathrm{S}$ e as longitudes $54^{\circ} 31^{\prime} \mathrm{W}$ e $54^{\circ} 26^{\prime} \mathrm{W}$, perfazendo uma área total de 3.637 ha (Figura 1).

\section{Fonte de Dados}

Para o desenvolvimento deste trabalho, foram utilizadas as seguintes fontes de dados:

- Imagem do sensor ETM+ (Enhanced Thematic Mapper plus) do satélite Landsat 7, órbita/ponto 225/072 de 29/07/2000 e 12/08/2008 adquirida junto à base de dados do GLCF (Global Land Cover Facility) georreferenciada e ortorretificada com resolução espacial de $15 \mathrm{~m}$ (banda 8 pancromática); Imagens do sensor ETM+ Landsat 7 de 17/06/2002 e TM (Thematic Mapper) do satélite Landsat 5 órbita/ponto 225/072 de 17/08/2004, 22/07/2006 e 12/08/2008 adquiridas junto ao INPE, com resolução espacial de $30 \mathrm{~m}$ para as bandas 3, 4 e 5; Imagem pancromática do sensor HRC do satélite sino-brasileiro CBERS-2B, órbita/ponto 164_C/119_1 de 06/07/2008, adquirida junto ao INPE, com resolução espacial de 2,7 m.

- Polígono (shape file) de perímetro da Fazenda Santo Antônio do Jurigue adquirido junto à base de dados de propriedades rurais licenciadas da SEMA-MT (Secretaria Estadual de Meio Ambiente de Mato Grosso).

Para o processamento digital das imagens foi utilizado o software ENVI $4.5 \mathrm{e}$ para elaboração dos layouts finais dos mapas foi utilizado o Sistema de Informações Geográficas ArcGIS 9.2.

\section{Procedimentos Metodológicos}

O desenvolvimento deste trabalho inicia-se com a aquisição junto ao GLCF da banda 8 pancromática ETM+ Landsat 7 do 


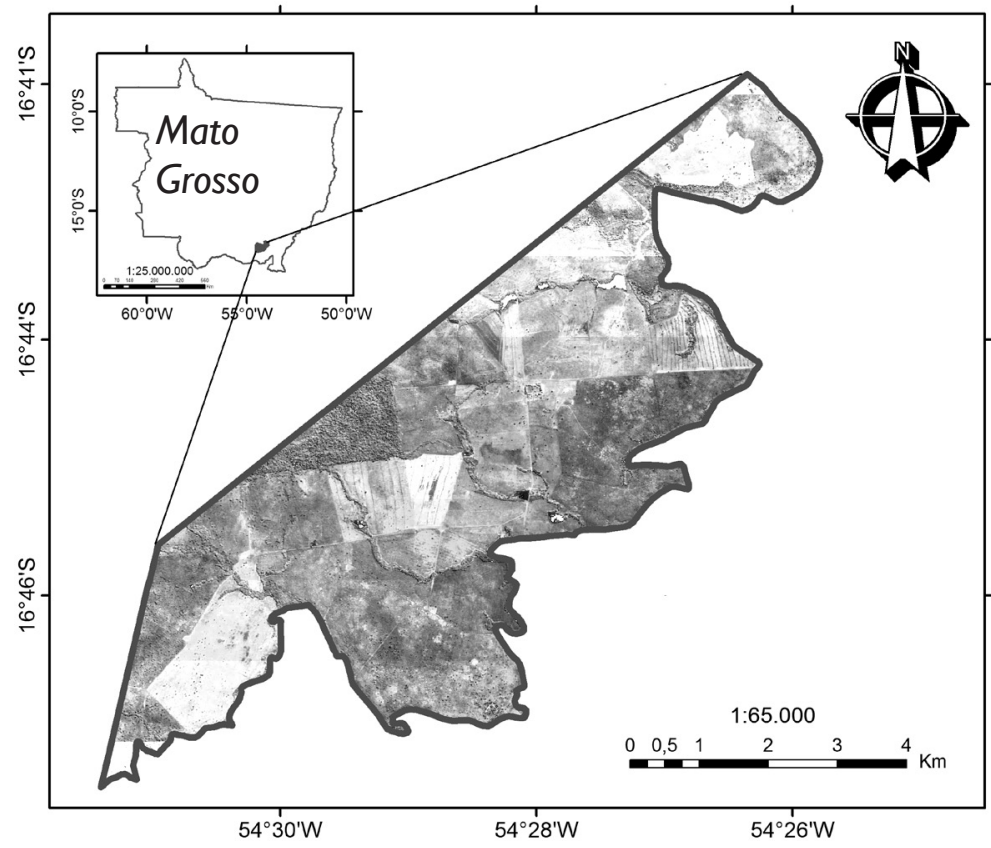

Figura I. Localização da área de estudo

ano de 2000, devidamente georreferenciada e ortorretificada que serviu como base para a correção geométrica da imagem HRC do satélite CBERS-2B e também para as imagens Landsat das demais épocas (2002, 2004, 2006 e 2008).

Com o recebimento, através do INPE, das bandas da imagem ETM+ Landsat 7, do ano de 2002 e das imagens TM Landsat 5, dos anos de 2004, 2006 e 2008, foram escolhidas as bandas 5, 4 e 3 para a elaboração da composição colorida (5R4G3B) com o intuito de ampliar o poder de discriminação dos alvos da área de estudo.

Para o ano de 2008 foi empregado o método de fusão de imagens IHS intensidade ("intensity"-I), matiz ("bue"-H) e saturação ("saturation" - S), que envolveu a imagem pancromática de alta resolução espacial do sensor HRC CBERS-2B e a composição RGB-543 obtida com os dados multiespectrais provenientes do sensor TM Landsat 5 (Figura 2). Objetivou-se com o uso desse método realçar a imagem e possibilitar a realização de análises em uma escala de trabalho mais refinada.

O processo de fusão de imagens IHS é descrito por Schetselaar (1998), Mather (1999), Gonzalez e Woods (2000) e Tu et al., (2001). A técnica consiste em realizar uma combinação de imagens no sistema de cores vermelho $(R)$, verde $(G)$ e azul (B), para produzir as componentes: intensidade (I), que representa a energia total envolvida; matiz $(\mathrm{H})$, que representa a cor dominante ou a medida do comprimento de onda médio da luz que foi refletida ou transmitida, e saturação (S), que expressa o intervalo de comprimento de onda ao redor do comprimento de onda médio, no qual a energia é refletida ou transmitida. Com a obtenção dessas componentes, substitui-se 

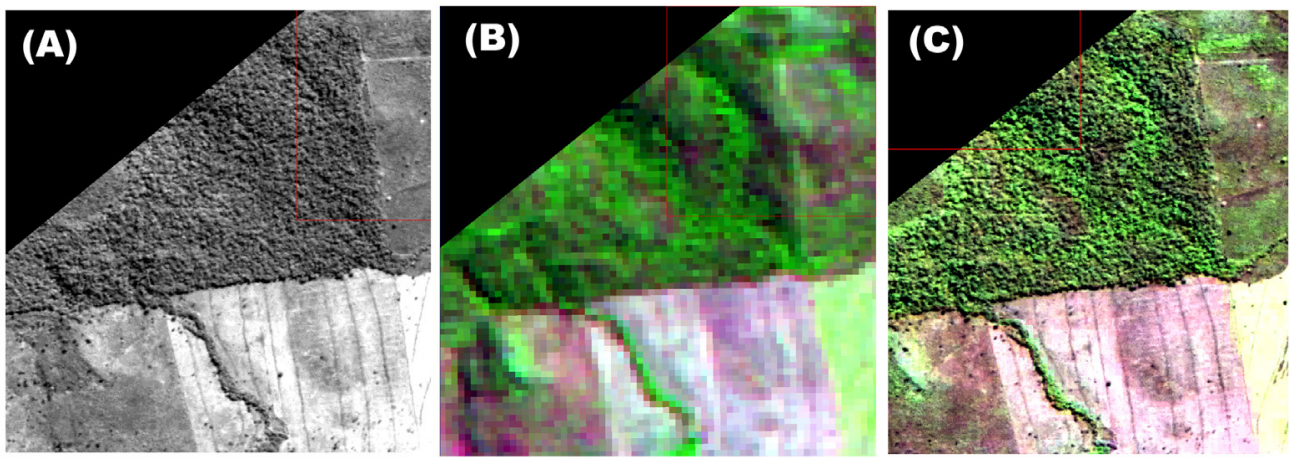

Figura 2. (A) Imagem HRC com resolução espacial de 2,7m; (B) Imagem TM com resolução espacial de $30 \mathrm{~m}$ e (C) Imagem Fusionada HRC/TM com resolução espacial de 2,7 m

a componente I pela imagem pancromática, de maior resolução espacial, no procedimento de retorno ao domínio RGB. Dessa maneira, a informação espectral da composição RGB é integrada à informação espacial da banda pancromática, tendo-se como produto final do processo de fusão uma imagem com resolução espacial de 2,7 metros, possibilitando uma escala de trabalho de 1:40.000 a até $1: 25.000$, conforme resultados obtidos por Rodrigues et al. (2009).

Com a imagem fusionada de 2008, por apresentar uma alta resolução espacial, tornase complicado o processo de classificação digital por máxima verossimilhança visando à distinção dos usos da terra. Por este motivo, procurou-se utilizar a técnica de processamento digital de imagens denominada classificação orientada a objetos. Luz et al., (2009) relatam que, nessa nova abordagem de processamento, na qual a unidade primitiva de processamento não é mais o pixel, e sim objetos compostos por vários pixels oriundos do processo de segmentação, este método subdivide a imagem em regiões homogêneas significativas baseadas não somente em propriedades espectrais, mas também na forma, textura, tamanho e outras características topológicas
(BENZ et. al, 2004). Os pares de objetos com o menor aumento na variância são mesclados. $\mathrm{O}$ processo termina quando o menor aumento está acima do limiar definido pelo usuário através do parâmetro de escala (RADOUXY; DEFOURNY, 2007).

A classificação orientada a objetos foi realizada pelo método do vizinho mais próximo, utilizando o módulo Envi Zoom do software Envi 4.5, através da ferramenta Feature Extraction, com a aplicação do processo de segmentação de imagens com um nível de escala de 40, e o parâmetro aplicado para reunião dos segmentos em subgrupos (merging segments) foi com um valor de 23,1.

A análise dos resultados foi realizada com base em mapas e tabelas resultantes do processo de classificação por máxima verossimilhança, com um limiar de aceitação de $95 \%$ para as séries temporais de 2002 , 2004, 2006 e 2008 e também através de classificação orientada a objetos aplicada na imagem do ano de 2008 fusionada, obtendo como resultado a dinâmica do nível de alteração da cobertura vegetal na propriedade.

Os dados obtidos foram agrupados em três classes (cobertura vegetal, área alterada e corpo d'água) ao longo dos anos, expressos em unidade de área (hectares) e 
em termos percentuais em relação à área total da propriedade. Para a delimitação da classe cobertura vegetal foram englobados quatro tipos de áreas: campo limpo, campo sujo, cerrado típico, matas ripárias e a área de reserva legal. Já classe área alterada são as áreas onde as tipologias da classe cobertura vegetal sofreram algum tipo de alteração, por meio da implantação de pastagens, poços de água e desmatamento para extração de lenha.

Para a quantificação da Área de Reserva Legal foram utilizados os resultados obtidos pela classificação orientada a objetos.

As análises temporais relacionadas aos resultados de áreas alteradas foram divididas da seguinte forma: (i) análise por época (2002, 2004, 2006 e 2008), (ii) análise por variação das áreas alteradas por detecção de mudanças de um período para o outro (20022004, 2004-2006, 2006-2008 e 2002-2008) e (iii) análise da ARL (Área de Reserva Legal), levando em consideração o percentual mínimo exigido para uma propriedade rural situada no bioma de cerrado (35\%) segundo a Medida Provisória No 2.166-67 de 24/08/2001.

\section{Resultados e Discussão}

\section{Análise por época}

A partir do método de classificação supervisionada por máxima verossimilhança, empregado nas imagens ETM+ e TM de média resolução espacial, foi obtida a dinâmica de alteração da cobertura vegetal por época na área investigada (3637 ha) (Figura 3). O nível de alteração da cobertura vegetal no ano de 2002 já atingia 33,43\%, percentual esse que aumentou para $40,32 \%$ em 2004, 51,85\% em 2006 e 60,69\% para o ano de 2008 .
Ao analisar os resultados da classificação orientada a objetos, aplicada na imagem fusionada HRC CBERS-2B com a TM Landsat 5 para o ano de 2008, verificou-se que 2.569 ha, correspondendo a $70,64 \%$ da área total, sofreram algum tipo de alteração da cobertura vegetal. Comparando esses resultados obtidos pelo método de classificação orientada a objetos com os resultados apresentados pelo método de classificação por máxima verossimilhança, foi verificada uma diferença de $9,95 \%$ a mais no nível de alteração entre esses métodos (Figura 4).

A classificação orientada a objetos aplicada na imagem fusionada propicia um melhor refinamento dos resultados dos alvos na superfície, por possuir uma maior resolução espacial quando comparada com a imagem TM, permitindo uma melhor distinção e quantificação das feições existentes. Estes resultados corroboram com o estudo desenvolvido por Monteiro et. al (2007), ao mapearem feições de florestas exploradas pela atividade madeireira na Amazônia meridional. Esses autores concluíram pelo bom desempenho da classificação orientada a objetos em imagens IKONOS, comparado àquelas de média resolução espacial (LANDSAT e ASTER). Luz et. al (2010) realizaram um mapeamento de uso da terra com o uso de imagens SPOT5 em uma área no interior do Estado do Paraná, por meio de técnicas de segmentação multiresolução e classificação orientada a objetos e, ao final, concluíram que a técnica utilizada apresentou resultados satisfatórios. Desclée et. al (2006) analisaram a utilização da classificação orientada a objeto para a detecção de alterações da cobertura florestal e concluíram que a precisão de detecção de mudanças realizadas pelo método orientado 
2002

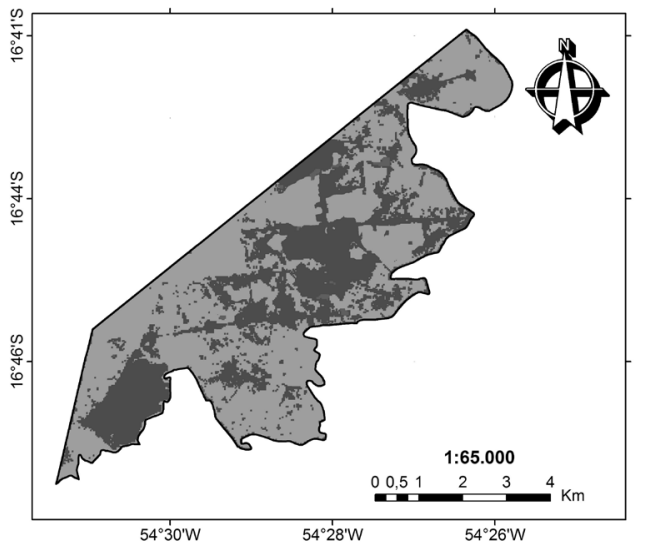

2006

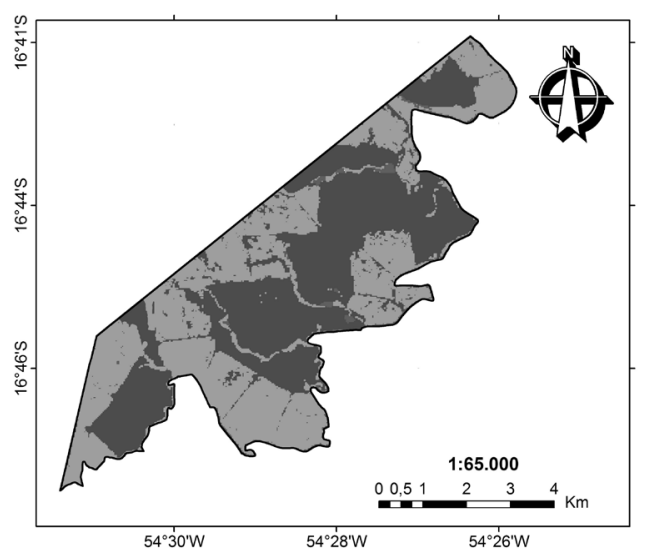

LEGENDA

COBERTURA VEGETAL

ÁREA ALTERADA

CORPO D'ÁGUA
2004

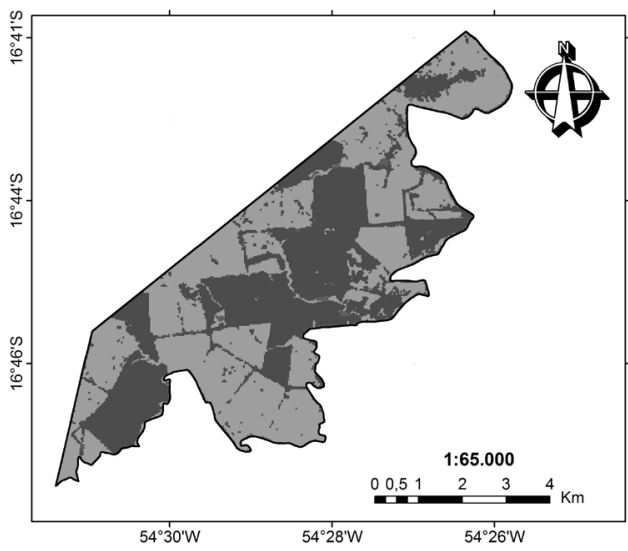

2008

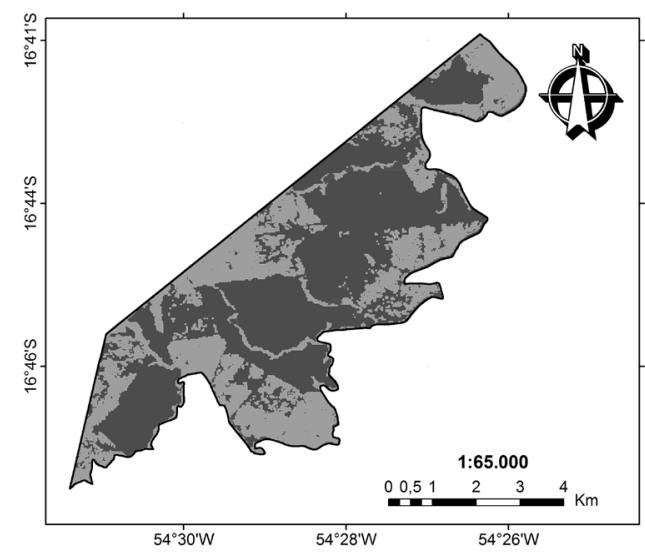

Figura 3. Dinâmica de alteração da cobertura vegetal utilizando classificação supervisionada por máxima verossimilhança

a objetos foram maiores do que os métodos baseados em pixels, independentemente da fonte de dados de validação. Myint et. al (2011) ao compararem a classificação pixela-pixel com a classificação orientada a objetos no mapeamento de áreas urbanas com o uso de imagens de alta resolução, verificaram que a classificação orientada a objetos é uma abordagem significativamente melhor que os classificadores clássicos por pixel.

\section{Análise por detecção de mudanças}

Ao analisar o período 2002-2004, foi verificado que a cobertura vegetal apresentou um nível de alteração de 250 ha. Para o período 2004-2006 foi observado o valor de 419 ha, sendo esse o período que apresentou o maior nível de alteração. No período de 2006-2008, utilizando para o ano de 2008 somente os resultados obtidos pela 

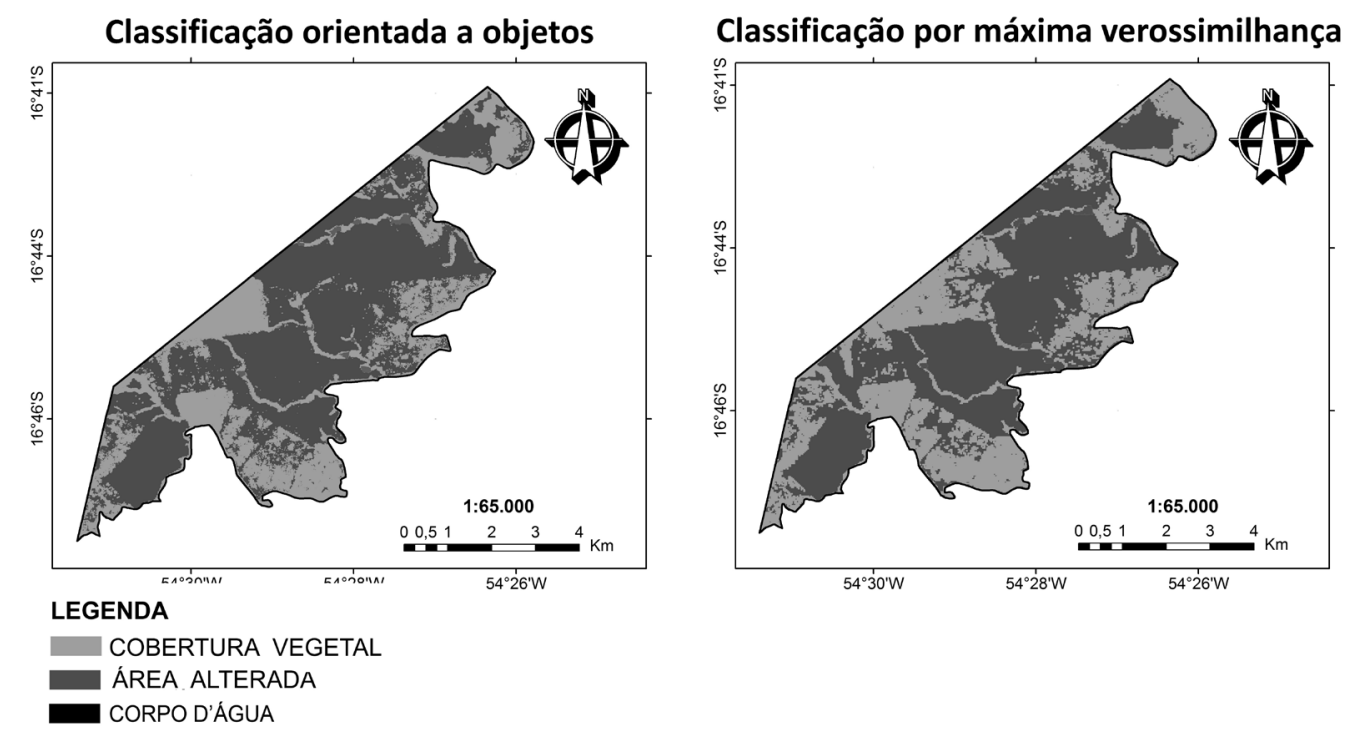

Figura 4. Comparação entre os métodos de classificação de imagens utilizados para o ano de 2008

classificação por máxima verossimilhança aplicada na imagem TM Landsat 5, foi verificado um nível de alteração de 321,80 ha, observando uma desaceleração do nível de alteração da cobertura vegetal em relação aos demais períodos. Porém, ao analisar o mesmo período (2006-2008), utilizando no ano de 2008 a imagem fusionada HRC CBERS-2B com a TM Landsat 5, com a aplicação da classificação orientada a objetos, o nível de alteração da cobertura vegetal apresentou um aumento de 683,58 ha.

Os dois resultados obtidos para o período 2006-2008 apresentam diferenças e estão relacionados aos métodos de classificação e fonte de dados envolvidos. No que se refere à quantificação do nível de mudanças, verifica-se que o método de classificação orientada a objetos produziu um mapa do nível de alteração da cobertura vegetal com boa exatidão temática para a área de estudo, pois a alta resolução espacial da imagem fusionada gerou um ganho efetivo na escala de detalhamento dos objetos geográficos possibilitando a melhor interpretação e desempenho do algoritmo classificador que foi utilizado na imagem. Isso resulta em um maior percentual de mudanças quando comparado às mudanças quantificadas utilizando a classificação por máxima verossimilhança.

Dessa forma, verifica-se que, do ano de 2002 (época em que ainda não havia iniciado um elevado grau de ocupação da terra e de uso dos recursos) até o ano de 2008, ocorreu uma aceleração crescente da dinâmica de expansão da substituição da cobertura vegetal, apresentando um nível de alteração de 991,56 ha analisando os valores obtidos pela classificação por máxima verossimilhança aplicada nos anos de 2002 e 2008, e 1.353,33 ha analisando a diferença entre os resultados obtidos pela classificação orientada a objetos aplicada na imagem fusionada do ano de 2008. Os resultados obtidos pela classificação orientada a objetos apresentaram maior área de cobertura vegetal alterada. Todavia, em ambas as análises, foi 
observado um aumento no nível de alteração da cobertura vegetal.

De acordo com esses dados, caso essa aceleração do nível de alteração da cobertura vegetal continue nessa mesma perspectiva, pode vir a ocasionar sérios prejuízos ambientais ao local, tais como perda da fertilidade do solo, assoreamento e contaminação dos cursos d'água, redução da disponibilidade hídrica do local, dentre outros agravos.

\section{Análise da Área de Reserva Legal}

Na quantificação da Área de Reserva Legal da propriedade, foi observado um valor de 158,56 ha $(4,36 \%)$ de reserva. Ao levar em consideração a Medida Provisória $\mathrm{N}^{\circ}$. 2.166-67 de 24.08.2001, verifica-se que a propriedade encontra-se irregular, sendo obrigatória a adesão do proprietário ao TAC (Termo de Ajuste de Conduta) ou ao TCC (Termo de Compromisso de Compensação) junto à Secretaria Estadual de Meio Ambiente de Mato Grosso, devendo recompor os $30,64 \%$ de reserva legal restante.

O TAC, firmado entre o proprietário do imóvel e a Secretaria Estadual de Meio Ambiente apresenta as seguintes possibilidades:

Pode-se recompor a reserva legal da propriedade mediante o plantio de espécies nativas, através da elaboração de um PRAD (Plano de Recuperação de Área Degradada), respeitando a ecologia da floresta e num prazo máximo para recuperação que pode chegar a 30 anos. Pode ser permitido plantio de árvores frutíferas, ornamentais ou industriais, compostas por espécies exóticas cultivadas em sistema intercalado com espécies nativas ou consórcio.
A condução da regeneração natural também é uma possibilidade de recomposição de reserva legal, devidamente avaliado pela Secretaria Estadual do Meio Ambiente, e também possui duração máxima de 30 anos.

Já o TCC apresenta outra possibilidade ao proprietário: a compensação da reserva legal por outra área equivalente em importância ecológica e extensão, desde que pertença ao mesmo ecossistema e esteja localizada na mesma microbacia hidrográfica.

\section{Conclusões}

A dinâmica de expansão da substituição da cobertura vegetal apresentou uma aceleração crescente ao longo dos anos, sendo que para o ano de 2008, a metodologia de classificação orientada a objetos foi a que apresentou resultados finais mais promissores possibilitados pelo uso de dados de alta resolução do sensor HRC do satélite CBERS-2B.

O uso do método de fusão com a transformação IHS associado a obtenção de um maior nível de informação a partir dos dados do sensor HRC do CBERS$2 \mathrm{~B}$, proporcionou a melhora no processo de classificação, demonstrando um maior detalhamento das feições. Destaca-se também, a possibilidade de utilização de dados deste sensor considerando-se a facilidade de acesso sem nenhum custo e sua aplicação na área ambiental ser perfeitamente viável.

No ano de 2008 a propriedade apresentou o percentual de 4,36\% de Reserva Legal, consideravelmente inferior ao mínimo exigido (35\%) pela Medida Provisória 2.166/67. O proprietário deverá aderir ao TAC (Termo de Ajuste de Conduta) ou ao TCC (Termo de Compromisso de 
Compensação) junto à Secretaria Estadual de Meio Ambiente de Mato Grosso, a fim de regularizar e enquadrar a Área de Reserva Legal ao percentual mínimo exigido em Lei.

\section{Referências}

BASEGGIO, J.; CARAMORI, T. B. A.; SORIANE, R. R. SIG para mapeamento do uso do solo, com ênfase nas áreas de cobertura vegetal nativa e recursos hídricos, Alto Coxim, MS. In: SIMPÓSIO DE GEOTECNOLOGIAS NO PANTANAL, 1., 2006, Campo Grande. Anais... Campinas: Embrapa Informática Agropecuária; São José dos Campos: INPE, 2006. p. 312-320. CD-ROM.

BENZ, U.; HOFMANN, P.; WILLHAUCK, G.; LINGENFELDER, I.; HEYNEN, M. Multi-resolution, object-oriented fuzzy analysis of remote sensing data for GIS-ready information.Journal of Photogrammetry and Remote Sensing, v. 58, n.3-4, p.239-258, 2004.

BRASIL. Lei $N^{\circ}$ 4.771-65, de 1518 de Setembro de 1965. Diário Oficial [da] República Federativa do Brasil, Brasília (DF), 15 de dezembro de 1965.

BRASIL. Medida Provisória no 2.166-67 de 24 de Agosto de 2001. Diário Oficial [da] República Federativa do Brasil, Brasília (DF), 24 de agosto de 2001.

BRUZZONE, L.; SMITS, P.C.; TILTON, J.C. Foreword: Special issue on analysis of multitemporal remote sensing images. Geoscience and Remote Sensing, IEEE Transactions on, v.41, n.11, p. 2419-2422, nov.2003.

COELHO, D. J. S.; SOUZA, A. L.; OLIVEIRA, C. M. L. Levantamento da cobertura florestal natural da microrregião de Viçosa, MG, utilizando-se de imagens Landsat 5. Revista Árvore, Viçosa, v.29, n.1, p. 17-24, 2005.

COPPIN, P.; JONCKHEERE, I. ; NACKAERTS, K.; MUYS, B.; LAMBIN, E. Review article digital change detection methods in ecosystem monitoring: a review. International Journal of Remote Sensing, [S.I], v. 25, n. 9, p. 1565-1596, 2004.

DESCLÉE, B.; BOGAERT, P.; DEFOURNY, P. Forest change detection by statistical object-based method. Remote Sensing of Environment, v. 102, n. 1-2, p. 1-11, jan.2006.

FIGUEIREDO, S.M.M.; CARVALHO,L.M.T. Avaliação da exatidão do mapeamento da cobertura da terra em capixaba, Acre, utilizando classificação por árvore de decisão. Revista Cerne, Lavras, v.12, n.1, p. 38-47, jan./mar. 2006.

GONZALEZ, R. C.; WOODS, R. E. Processamento de imagens digitais. São Paulo: Edgard Blücher, 2000. 509 p. 
LORENA, R. B.; SANTOS, J. R.; SHIMABUKURO, Y. E.; BROWN, I. F.; KUX, H. J. $\mathrm{H}$. A change vector analysis technique to monitor of landuse/land cover in SW Brazilian Amazon, Acre State. In: PECORA 15 - Integrating Remote Sensing at the Global, Regional and Local Scale. Proceedings. Denver, Colorado/USA, Nov., p. 8-15, 2002. CDROM.

LUZ, N. B.; ANTUNES, A. F. B.; TAVARES JUNIOR, J. B. Segmentação multirresolução e classificação orientada a objetos aplicados a imagens SPOT-5 para o mapeamento do uso da terra. Revista Floresta, Curitiba, v.40, n.2, p. 429-446, 2010.

MALDONADO, F. D.; SANTOS, J. R.; CARVALHO, V. C. Land use dinamics in the semi-arid region of Brazil (Quixabá-PE): caracterization by principal components analysis. International Journal of Remote Sensing, v. 23, n. 23, p. 5005-5013, 2002.

MÁS, J. F. Monitoring land-cover changes: a comparison of change detection techniques. International Journal of Remote Sensing, v. 20, n. 1, p. 139 - 152, 1998.

MATHER, P. M. Computer processing of remotely-sensed images: an introduction. Chichester: John Wiley \& Sons, 1999. 292 p.

MONTEIRO, A.; LINGNAU, C.; SOUZA JUNIOR, C. Classificação orientada a objeto para a detecção da exploração seletiva de madeira na Amazônia. Revista Brasileira de Cartografia, Rio de Janeiro, v.3, n.59, p. 225-234, 2007.

MYINT, S. W.; GOBER, P.; BRAZEL, A.; GROSSMAN-CLARKE, S.; WENG, Q. Per-pixel vs. object-based classification of urban land cover extraction using high spatial resolution imagery. Remote Sensing of Environment, 2011. v. 115, n.5, p.1145-1161, doi:10.1016/j.rse.2010.12.017

OLIVEIRA FILHO,P.C.; DISPERATI,A.A.; KIRCHNER, F.F.Análise de dados digitais multiespectrais de alta resolução obtidos pelo sensor "Compact Airborne Spectrographic Imager” em área rural do estado do Paraná - Brasil. Revista Cerne, Lavras, v.4, n.1, p. 0121, 1998.

RADOUX,J.; DEFOURNY,P. A quantitative assessment of boundaries in automated forest stand delineation using very high resolution imagery. Remote Sensing of Environment, v. 110, n. 4, p. $468-475$, fev.2007.

RODRIGUES, T. L.; ANTUNES, M. A. H.; FOSSE, J. M. Avaliação da ortoretificação da imagem do sensor HRC do CBERS 2B utilizando modelo de funções racionais. In: SIMPOSIO BRASILEIRO DE SENSORIAMENTO REMOTO, 13., 2009, Natal. Anais... Natal: XIV - SBSR/INPE, p. 2139-2146, 2009.

SANTOS, J. R.; MALDONADO, F. D.; GRAÇA, P. M. L. A. Integração de Imagens LANDSAT/ETM+ e CBERS-2/CCD para Deteç̧ão de Mudanças em área da Amazônia sob domínio da Floresta de Transição. Revista Brasileira de Cartografia, n. 57, n. 1, p.1521, Rio de Janeiro, 2005. 
SCHETSELAAR, E.M. Fusion by the IHS transform: should we use cylindrical or spherical coordinates? International Journal of Remote Sensing, Basingstoke, v.19, n.4, p.759-65, 1998.

SILVA, P. G.; SANTOS, J. R.; SHIMABUKURO, Y. E.; GRAÇA, P. M. A.; SOUZA, P. E. U. Change vector analysis technique to monitor selective logging activities in Amazon tropical rainforest. In: IEEE International Geoscience and Remote Sensing Symposium: Learning from Earth's Shapes \& Colors - IGARSS. 2003. Toulouse, France, Proceedings. Jul., 21-25, 2003. CDROM.

TU, T.; SU, S.; SHYU, H.; HUANG, P. S. Efficient intensity-hue-saturation-based image fusion with saturation compensation. Optical Engineering, Redondo Beach, v.40, n.5, p.720-8, 2001. 